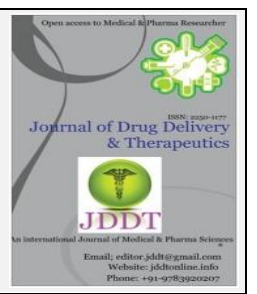

Open Access

Research Article

\title{
Study of Prevalence Rate, Side Effect and Co-Morbidities Associated with Current Drug Therapy in Patients Suffering with Nephrotic Syndrome
}

\author{
Abhishek Prasad *1, Prashant Mathur ${ }^{2}$ \\ ${ }^{1}$ Student, Pharm D(PB), Department of Pharmacy Practice, School of Pharmaceutical Sciences, Shri Guru Ram Rai University, Patel Nagar, \\ Dehradun, Uttarakhand, 248001, India.
}

${ }^{2}$ Associate Professor (HOD), Department of Pharmacy Practice, School of Pharmaceutical Sciences, Shri Guru Ram Rai University, Patel Nagar, Dehradun, Uttarakhand, 248001, India.

\begin{abstract}
Background: Nephrotic syndrome is a kidney disease caused by damage to the cluster of small blood vessels in the kidney. Nephrotic syndrome causes misfunctioning of the kidney that affects metabolism of the body significantly. It causes complications of blood clots, high blood cholesterol and elevated blood triglycerides, poor nutrition, high blood pressure, acute kidney failure, chronic kidney disease and various infections.

Objectives: The present investigation was objected to study prevalence rate, side effect of prescribed drugs and co-morbidity associated with current drug therapy in patient suffering with nephrotic syndrome.

Methodologies: The present observational study was conducted on 43 nephrotic syndrome patients. These patients were evaluated for effects and side effects of prescribed drugs. Co-morbidity related to drug current prescribed was assessed and prescribed drugs for co-morbidity for also assessed. Prevalence rate of nephrotic syndrome was calculated among the all investigated patients. Patients were investigated who signed consent form. Patients above 18 years of age were excluded from study.

Results: The involved 43 patients of nephrotic syndrome. These patients were prescribed with Corticosteroids (27\%), Immunomodulator (8\%), Immunosuppressant (5\%), Diuretics (20\%), ACE Inhibitors (5\%), Angiotensin II receptor antagonist (5\%). Co-morbidity were related to current drugs were observed and it was found that $9(20 \%)$ patients were suffering from asthma, 3 (7\%) patients were suffering epilepsy, 1 $(2 \%)$ patients were suffering from inflammatory bowel disease, $5(11 \%)$ patients were suffering from other diseases along with nephrotic syndrome. Prevalence rate of nephrotic syndrome was found $2.38 \%$ in patients.

Conclusion: The present study revealed that the current prescribed drugs for nephrotic syndrome causes side effects that are skin infection, behavioral changes, blood in urine and decreased neutrophils. And co-morbidity of asthma, epilepsy, inflammatory bowel disease and other disease were present in patients of nephrotic syndrome. 1 patient out of every 42 investigated patients was suffering from nephrotic syndrome.
\end{abstract}

Keywords: Nephrotic syndrome, corticosteroids, side effects, co-morbidity and prevalence rate.

Article Info: Received 07 July 2019; $\quad$ Review Completed 12 Sep 2019; $\quad$ Accepted 20 Sep 2019; Available online 15 Oct 2019

Cite this article as:

Prasad A, Mathur P, Study of Prevalence Rate, Side Effect and Co-Morbidities Associated with Current Drug Therapy in Patients Suffering with Nephrotic Syndrome, Journal of Drug Delivery and Therapeutics. 2019; 9(5-s):11-17 http://dx.doi.org/10.22270/jddt.v9i5-s.3589

a

Abhishek Prasad, Student, Pharm D(PB), Department of Pharmacy Practice, School of Pharmaceutical Sciences, Shri Guru Ram rai University, Patel Nagar, Dehradun, Uttarakhand, 248001, India.

\section{INTRODUCTION:}

Nephrotic Syndrome is a rare disease found in pediatric patients. Nephrotic syndrome is a kidney disorder that results in misfunctioning of the nephrotic cells of the kidney. In nephrotic syndrome cluster of small blood vessels (glomeruli) in kidney are damaged. Nephrotic syndrome causes to excrete too much protein in urine and filtration process in kidney is severely affected. It is the second most frequent cause of chronic kidney disease in children. It is usually treated with corticosteroid drugs, but $15 \%$ of treated children do not respond to this type of drug. These causes may progress to chronic or end-stage kidney failure, requiring dialysis or transplantation.

My main aim was to check prevalence rate and side effect of the drugs used in comorbidities. Data collection from the 
tertiary hospital I analyzed that we need to check the prevalence rate and side effects of the drugs, so that the side effects can be reduced and better treatment for comorbid condition and also analyse drugs prescribed per perception.

Nephrotic syndrome is a kidney disorder that causes your body to excrete too much protein in your urine. Nephrotic syndrome is an important chronic disease in children, characterized by minimal change disease in the majority. [1]

Nephrotic syndrome is usually caused by damage to the clusters of small blood vessels in your kidneys that filter waste and excess water from your blood. Nephrotic syndrome causes swelling (edema), particularly in your feet and ankles, and increases the risk of other health problems.[1

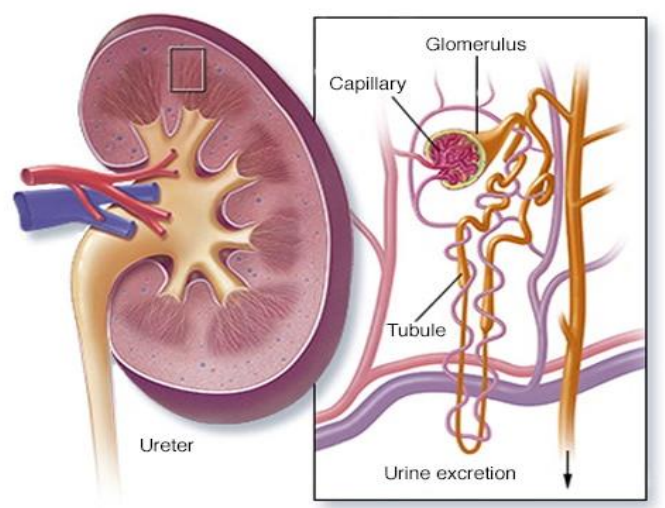

Fig 1: Cross section of kidney

Blood enters your kidneys through your renal arteries. Your kidneys remove excess fluid and waste material from your blood through units called nephrons. Each nephron contains a filter (glomerulus) that has a network of tiny blood vessels called capillaries. The glomeruli filter waste products and substances your body needs such as sodium, phosphorus and potassium which then pass through tiny tubules. The substances your body needs are reabsorbed into the blood. [2-3]

\section{Symptoms}

Signs and symptoms of nephrotic syndrome include:

- $\quad$ Severe swelling (edema), particularly around your eyes and in your ankles and feet

- $\quad$ Foamy urine, which may be caused by excess protein in your urine

- Weight gain due to excess fluid retention

- Fatigue

- $\quad$ Loss of appetite[2]

\section{Causes}

Nephrotic syndrome is usually caused by damage to the clusters of tiny blood vessels (glomeruli) of your kidneys.

The glomeruli filter your blood as it passes through your kidneys, separating things your body needs from those it doesn't. Healthy glomeruli keep blood protein (mainly albumin) which is needed to maintain the right amount of fluid in your body from seeping into your urine. When damaged, glomeruli allow too much blood protein to leave your body, leading to nephrotic syndrome.[2]

\section{Many Possible Causes}

Many diseases and conditions can cause glomerular damage and lead to nephrotic syndrome, including:[4,5,6,7]

- Diabetic kidney disease. Diabetes can lead to kidney damage (diabetic nephropathy) that affects the glomeruli.

- Minimal change disease. This is the most common cause of nephrotic syndrome in children. Minimal change disease results in abnormal kidney function, but when the kidney tissue is examined under a microscope, it appears normal or nearly normal. The cause of the abnormal function typically can't be determined.

- Focal segmental glomerulosclerosis. Characterized by scattered scarring of some of the glomeruli, this condition may result from another disease or a genetic defect or occur for no known reason.

- Membranous nephropathy. This kidney disorder is the result of thickening membranes within the glomeruli. The exact cause of the thickening isn't known, but it's sometimes associated with other medical conditions, such as hepatitis B, malaria, lupus and cancer.

- Systemic lupus erythematosus. This chronic inflammatory disease can lead to serious kidney damage.

- Amyloidosis. This disorder occurs when substances called amyloid proteins accumulate in your organs. Amyloid buildup often affects the kidneys, damaging their filtering system.

- Blood clot in a kidney vein. Renal vein thrombosis, which occurs when a blood clot blocks a vein connected to the kidney, can cause nephrotic syndrome.

\section{Who is at a risk of nephrotic syndrome?}

Anyone can get nephrotic syndrome but it is slightly more common in men than in women. In children, it happens most often between the ages of 2 and 6 . it's usually first diagnosed in children aged between 2 and 5 years old. It affects more boys than girls. Around 1 in every 50,000 children are diagnosed with the condition each year. There are other factors that may increase your risk. [3-4]

Treatment is directed at the underlying cause. Other efforts include managing high blood pressure, high blood cholesterol, and infection risk. A low salt diet and limiting fluids is often recommended. About 5 per 100,000 people are affected per year. The usual underlying cause varies between children and adults. [5]

\section{Types of Nephrotic Syndrome?}

Nephrotic syndrome has many causes and may either be the result of a glomerular disease that can be either limited to the kidney, called primary nephrotic syndrome (primary glomerulonephrosis), or a condition that affects the kidney and other parts of the body, called secondary nephrotic syndrome. [8-10] 


\section{CLASSIFICATION}

A broad classification of nephrotic syndrome based on underlying cause:

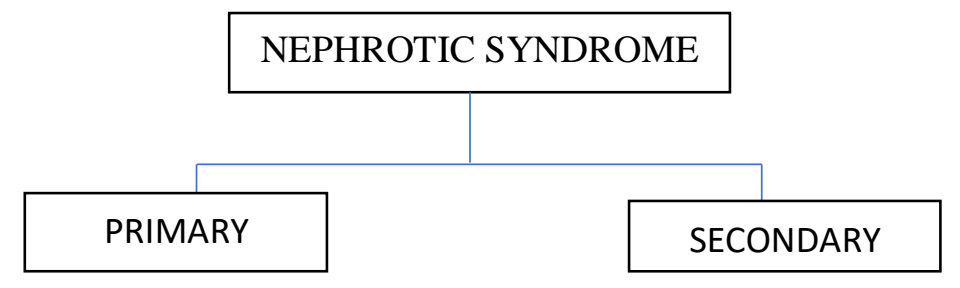

Nephrotic syndrome is often classified histologically.

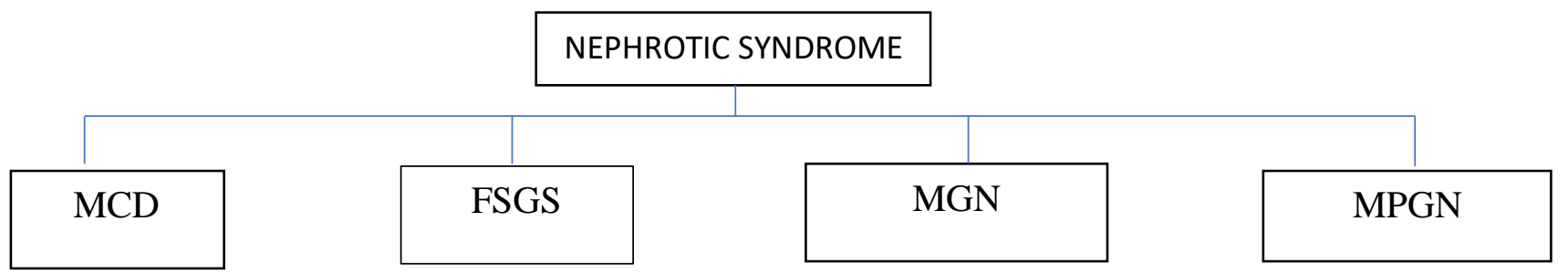

\section{Signs and Symptons}

Nephrotic syndrome is characterized by large amounts of proteinuria $\left(>3.5 \mathrm{~g}\right.$ per $1.73 \mathrm{~m}^{2}$ body surface area per day, ${ }^{[21]}$ or $>40 \mathrm{mg}$ per square meter body surface area per hour in children), hypoalbuminemia $(<2,5 \mathrm{~g} / \mathrm{dl})$, hyperlipidaemia, and edema that begins in the face. Lipiduria (lipids in urine) can also occur,but is not essential for the diagnosis of nephrotic syndrome. Hyponatremia also occurs with a low fractional sodium excretion.

\section{Complications}

Possible complications of nephrotic syndrome include:[9,10]

- Blood clots. The inability of the glomeruli to filter blood properly can lead to loss of blood proteins that help prevent clotting. This increases your risk of developing a blood clot (thrombus) in your veins.

- High blood cholesterol and elevated blood triglycerides. When the level of the protein albumin in your blood falls, your liver makes more albumin. At the same time, your liver releases more cholesterol and triglycerides.

- Poor nutrition. Loss of too much blood protein can result in malnutrition. This can lead to weight loss, but it may be masked by swelling. You may also have too few red blood cells (anemia) and low levels of vitamin D and calcium.

- High blood pressure. Damage to your glomeruli and the resulting buildup of wastes in your bloodstream (uremia) can raise your blood pressure.

- $\quad$ Acute kidney failure. If your kidneys lose their ability to filter blood due to damage to the glomeruli, waste products may build up quickly in your blood. If this happens, you may need emergency dialysis an artificial means of removing extra fluids and waste from your blood typically with an artificial kidney machine (dialyzer).

- Chronic kidney disease. Nephrotic syndrome may cause your kidneys to gradually lose their function over time. If kidney function falls low enough, you may require dialysis or a kidney transplant.

- Infections. People with nephrotic syndrome have an increased risk of infections.

\section{Risk Factors}

Factors that can increase your risk of nephrotic syndrome include:[2-3]

- Medical conditions that can damage your kidneys. Certain diseases and conditions increase your risk of developing nephrotic syndrome, such as diabetes, lupus, amyloidosis and other kidney diseases.

- Certain medications. Examples of medications that can cause nephrotic syndrome include nonsteroidal anti-inflammatory drugs and drugs used to fight infections.

- Certain infections. Examples of infections that increase the risk of nephrotic syndrome include HIV, hepatitis $B$, hepatitis $C$ and malaria.

\section{Diagnosis of Nephrotic Syndrome}

Along with obtaining a complete medical history a series of biochemical tests are required in order to arrive at an accurate diagnosis that verifies the presence of the illness. In addition, imaging of the kidneys (for structure and presence of two kidneys) is sometimes carried out, and/or a biopsy of the kidneys. The first test will be a urinalysis to test for high levels of proteins, as a healthy subject excretes an insignificant amount of protein in their urine.

\section{The tests are given below:}

$$
\begin{aligned}
& \text { * Urine test } \\
& \text { * Blood test } \\
& \text { * Removing a sample of kidney tissue for testing. }
\end{aligned}
$$

\section{Treatment of Nephrotic Syndrome}

Treatment for nephrotic syndrome involves treating any underlying medical condition that may be causing your nephrotic syndrome. 
Medications may include:[11]

- Blood pressure medications.[12]

- Water pills.[13]

- Cholesterol-reducing medications. [14]

- Blood thinners. [15-16]

- Immune system-suppressing medications. [17-19]

\section{What is Comorbidity?}

Comorbidity is a term you might hear pretty frequently in psychology as well as in medicine more broadly. It is important to understand comorbidity and how it works so that you can evaluate and help comorbid patients, or patients that are suffering from multiple, related diseases or disorders at the same time. In psychology, comorbidity refers to more than one disorders or diseases that exist alongside a primary diagnosis, which is the reason a patient gets referred and/or treated.[22]

\section{Prevalence:}

The proportion of individuals in a population having a disease or characteristic. Prevalence is a statistical concept referring to the number of cases of a disease that are present in a particular population at a given time, whereas incidence refers to the number of new cases that develop in a given period of time.[23]

\section{MATERIALS AND METHOD:}

The study was conducted in Tertiary Care Hospital, Dehradun. The Patients attending the Inpatient facilities of the department of Pediatric ward with clinical diagnosis of Nephrotic Syndrome were included in the study. This was present observational study which was conducted on 43 nephrotic syndrome patients. These patients were evaluated for effects and side effects of prescribed drugs. Co-morbidity related to drug current prescribed was assessed and prescribed drugs for co-morbidity for also assessed. Prevalence rate of nephrotic syndrome was calculated among the all investigated patients. Patients were investigated who signed consent form. Patients above 18 years of age were excluded from study.

\section{RESULTS:}

The study was conducted on 43 patients for prevalence rate, side effect and co-morbidities associated with nephrotic syndrome among inpatient of pediatric care unit at SHRI MAHANT INDIRESH HOSPITAL, DEHRADUN. All subjects satisfy the inclusion and exclusion criteria were included as the study population. The data which were collected, analyzed and evaluated to get the accurate results.

\section{Gender categorization}

According to the data collected in study, among 43 patients 36 were males and 07 were females accounting for $84 \%$ and $14 \%$ respectively as shown in table 1 and figure 1.

Table no 1 Gender distribution of the patient:

\begin{tabular}{|c|c|c|}
\hline Gender & No. of patients & Percentage \% \\
\hline Male & 36 & $84 \%$ \\
\hline Female & 07 & $16 \%$ \\
\hline Total & 43 & $100 \%$ \\
\hline
\end{tabular}

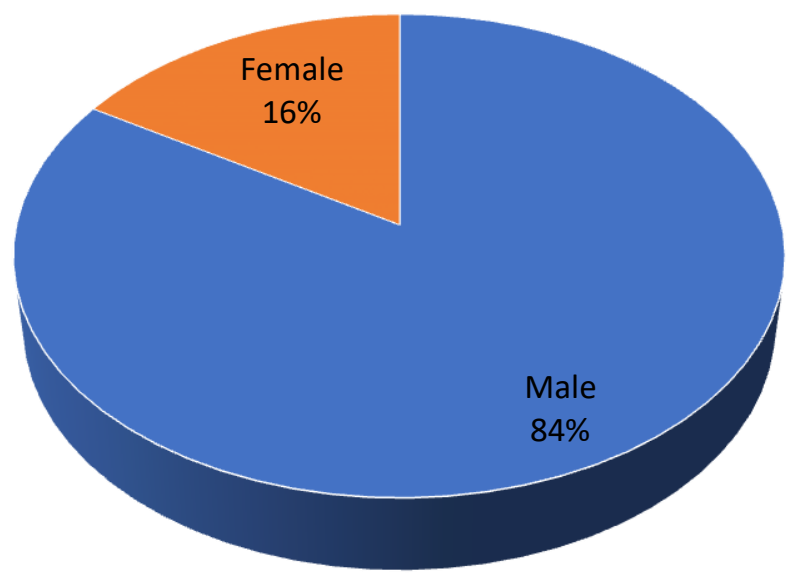

Figure 1. Representing the gender distribution of the patients.

\section{Age group categorization}

Out of 43 patients $28(65 \%)$ patients were in age group of 01-06 years, $09(21 \%)$ patients were in age group of 07-12 years, $06(14 \%)$ patients were in age group of 13-18 shown in table 2 and figure 2.

Table 2. Age classification in different categories:

\begin{tabular}{|c|c|c|}
\hline Age & No. of patients & Percentage \% \\
\hline $01-06$ & 28 & $65 \%$ \\
\hline $07-12$ & 09 & $21 \%$ \\
\hline $13-18$ & 06 & $14 \%$ \\
\hline
\end{tabular}

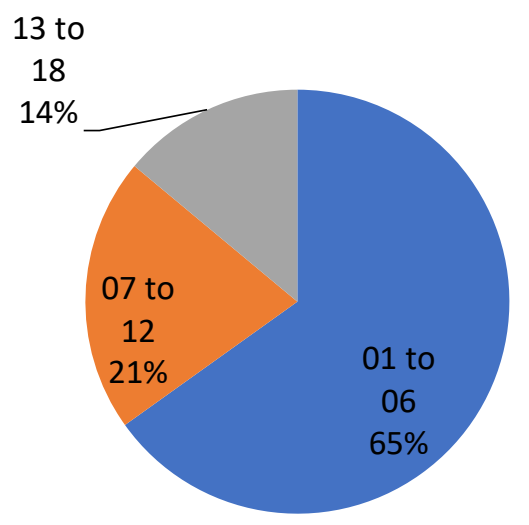

Figure 2. Representing the age group classification.

\section{Associated co-morbidities:}

According to this study out of 43 patients 09 (20\%) patients have a history of asthma, $03(7 \%)$ patients have a history of epilepsy, $02(4 \%)$ patients have a combine history of asthma and epilepsy, $01(2 \%)$ patient have a history of IBD and 02 (4\%) patients have a history of prematurity, $03(7 \%)$ patients have other condition associated with nephrotic syndrome infraction as shown in table 3 . and figure 3 . 
Table 3 Associated co-morbidities.

\begin{tabular}{|l|c|c|}
\hline Associated co-morbidities & $\begin{array}{c}\text { No. of } \\
\text { Patients }\end{array}$ & Percentage \% \\
\hline None & 27 & $60 \%$ \\
\hline Asthma & 09 & $20 \%$ \\
\hline Epilepsy & 03 & $7 \%$ \\
\hline $\begin{array}{l}\text { Inflammatory Bowel } \\
\text { Disease }\end{array}$ & 01 & $2 \%$ \\
\hline Prematurity & 02 & $4 \%$ \\
\hline Others & 03 & $7 \%$ \\
\hline
\end{tabular}

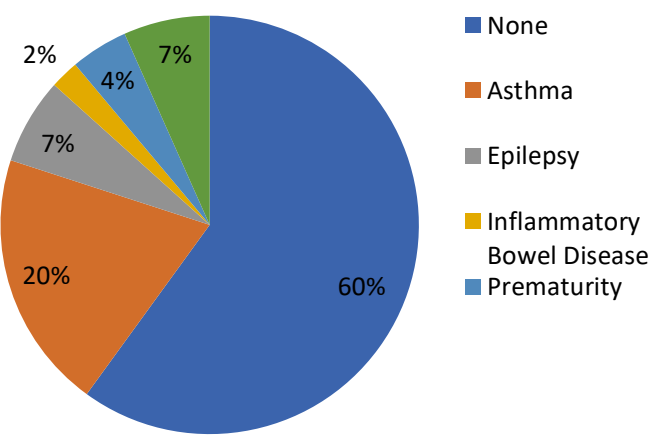

Figure 3. Representing the Associated co-morbidities

\section{Different categories of drugs prescribed in NS patients:}

According to this study, out of 43 patients, a total no. of 167 drugs was prescribed among patients of nephrotic syndrome. The study showed that Corticosteroids have been prescribed in most of the patients, followed by Immunomodulator, Diuretics, Immunosuppressant, Methylxanthine, ACE Inhibitor, Angiotensin II receptor antagonist, Sedatives, ACTH Analogue, Aminosalicylates and miscellaneous drugs as shown in table 4 and figure 4.

Table 4. Different categories of drugs prescribed in NS patients

\begin{tabular}{|l|c|c|}
\hline \multicolumn{1}{|c|}{ Drug class } & Frequency & Percentage \% \\
\hline Corticosteroids & 43 & $27 \%$ \\
\hline Immunomodulator & 13 & $08 \%$ \\
\hline Immunosuppressant & 08 & $05 \%$ \\
\hline Diuretics (ACE) & 31 & $20 \%$ \\
\hline $\begin{array}{l}\text { Angiotensin-converting } \\
\text { Enzyme } \\
\text { Inhibitors }\end{array}$ & 07 & $05 \%$ \\
\hline $\begin{array}{l}\text { Angiotensin II receptor } \\
\text { antagonist }\end{array}$ & 07 & $05 \%$ \\
\hline *Methylxanthine & 11 & $8 \%$ \\
\hline *Sedatives & 04 & $2 \%$ \\
\hline *Aminosalicylates & 02 & $1 \%$ \\
\hline Miscellaneous & 28 & $18 \%$ \\
\hline
\end{tabular}

*Drug used in co-morbidities

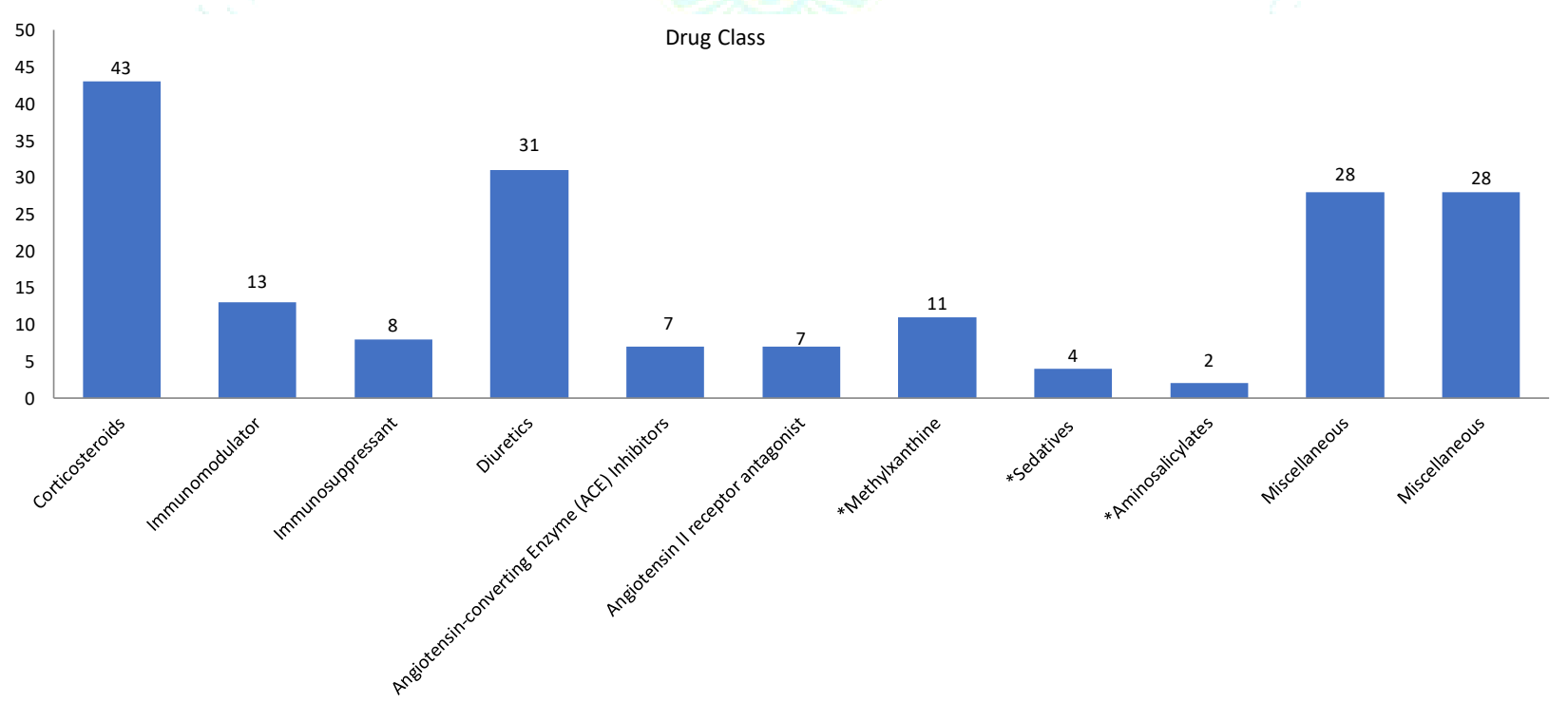

Figure 4. Representing different categories of drugs prescribed in NS patients Side effects associated with drug used in treatment of NS.

According to study, out of 43 patients, a total no. of 7 patients was found to have skin infection and 4 patients had behavioural change, 4 patients was found to have problem of blood in urine and 3 patients had decrease in Neutrophils.

Table 6 Side effects associated with drug used in treatment of NS.

\begin{tabular}{|l|c|c|}
\hline \multicolumn{1}{|c|}{ Side Effects } & No. of Patients & Percentage (\%) \\
\hline Skin Infection & 7 & $16 \%$ \\
\hline Behavioral change & 4 & $9 \%$ \\
\hline Blood in urine & 4 & $9 \%$ \\
\hline Decreased neutrophils & 3 & $7 \%$ \\
\hline
\end{tabular}




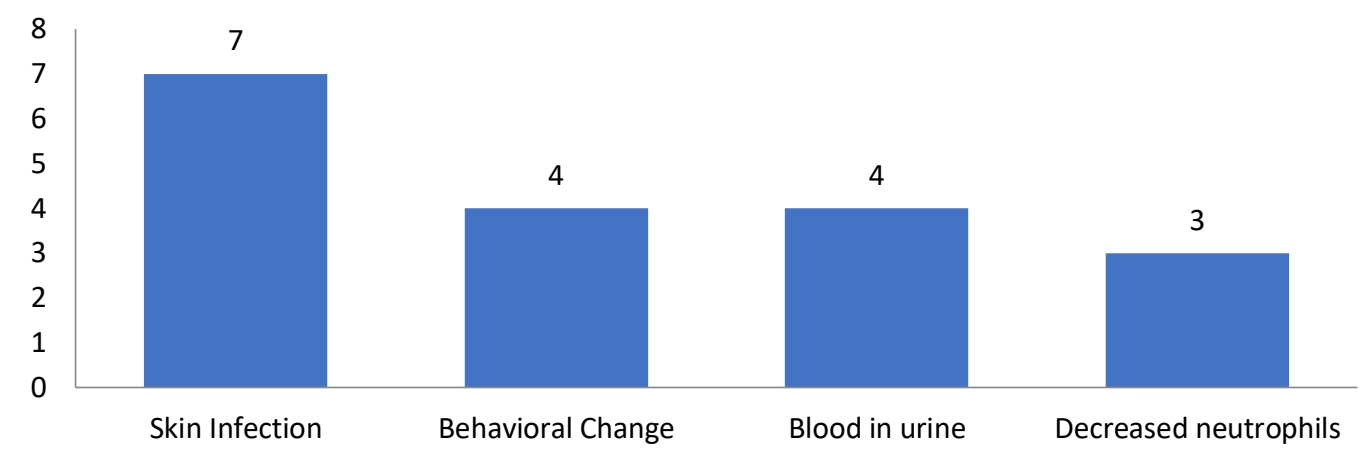

Figure 6. Side effect due to drug used in NS.

\section{Prevalence rate for NS.}

According to study, total no. of patient who is affected with nephrotic syndrome was 43 . This study was conducted in pediatric unit of Shri Mahant Indresh Hospital were total no. of patient who is admitted in pediatric ward in 6 month period was 1811 . Hence the prevalence rate for nephrotic syndrome in pediatric unit is

\section{Prevalence Rate $=$}

No. of patients in sample with characteristic

Total no. of patients in sample 43

Prevalence Rate $=\frac{}{1806}$
Prevalence Rate $=\frac{1}{42}$

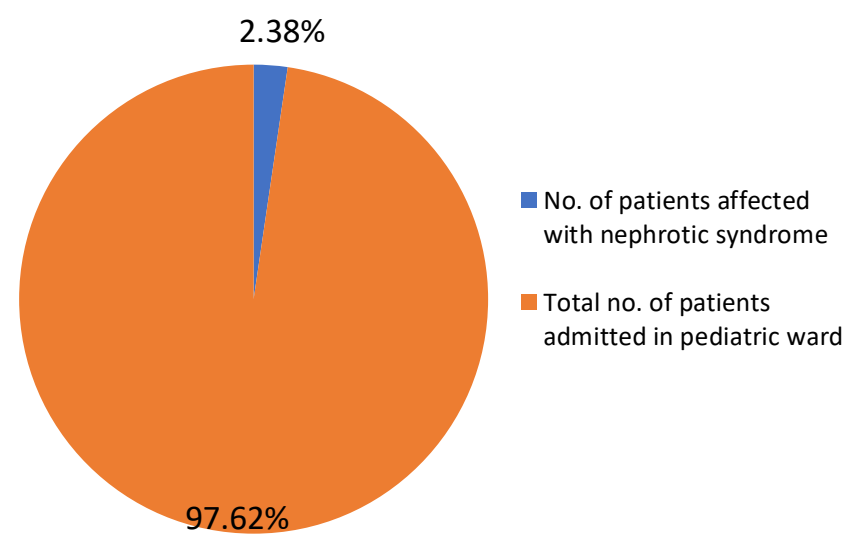

Figure 7. Prevalence rate for NS

\section{DISCUSSION:}

Nephrotic syndrome is a kidney disorder that results in misfunctioning of the nephrotic cells of the kidney. In nephrotic syndrome cluster of small blood vessels (glomeruli) in kidney are damaged. Nephrotic syndrome causes to excrete too much protein in urine and filtration process in kidney is severely affected. Nephrotic syndrome is an important chronic disease in children. Nephrotic syndrome is generally caused due to many metabolic disorders and diseases that are diabetes, hepatitis, minimal change disease, focal segmental glomerulosclerosis, membranous nephropathy, systemic lupus erythematosus and Amyloidosis. Nephrotic syndrome can cause serious complications including blood clots, high blood cholesterol and elevated blood triglycerides, poor nutrition, high blood pressure, acute kidney failure, chronic kidney disease and various infections.

The present study was conducted to analyze patients of nephrotic syndrome and assess the most commonly prescribed drug for it. The rational uses of prescribed drugs were evaluated and patients were counseled about nephrotic syndrome and prescribed drugs. Total 43 nephrotic syndrome cases were studied. Patients were suffering from severe swelling (edema), particularly around eyes and in ankles and feet, foamy urine caused by excess protein in urine, weight gain due to excess fluid retention, fatigue and loss of appetite.

The medication prescribed for them were Prednisone, Prednisolone (Orapred, Pediapred, Prelone), Diuretics, Furosemide (Lasix), Metolazone (Zaroxolyn), Plasma protein, Albumin (Albuminar, Buminate, Flexbumin, Plasbumin), Immunosuppressive agents, Mycophenolate mofetil (CellCept, Myfortic), and Tacrolimus (Prograf). These prescribed drugs also showed side effects on the patients. After counselling and medical investigation, it was found that the most common side effects of prescribed drugs were skin infection, behavioral changes, blood in urine and decreased neutrophils.

Co-morbidity related to nephrotic syndrome was also investigated in this study. It was found, along with nephrotic syndrome $9(20 \%)$ patients were also suffering from asthma, $3(7 \%)$ patients were suffering epilepsy, $1(2 \%)$ patients were suffering from inflammatory bowel disease, 5 (11\%) patients were suffering from other diseases.

In the co-morbid cases Methylxanthine was prescribed in 11 (25\%), Sedatives were prescribed in $4(9 \%)$, Amino salicylates were prescribed in $02(4 \%)$ patients followed by Miscellaneous Drug 28 (65\%).

In this study the prevalence rate of nephrotic syndrome was observed and it was found that 43 patients were found positive to nephrotic syndrome out of 1806 patients. Prevalence rate was $2.38 \%$ meaning that 1 out of every 42 investigated patients was suffering from nephrotic syndrome.

\section{CONCLUSION:}

In the present study, patients of nephrotic syndrome were investigated to find causes of nephrotic syndrome and prescribed drugs for it. Rational of prescribed drugs was assessed and side effects of prescribed drugs were evaluated. Co-morbidity related to nephrotic syndrome in patients was also investigated with prescribed drug for comorbidity. The prevalence rate of the nephrotic syndrome was also observed. 
Total 43 patients were found positive to nephrotic syndrome out of 1806 patients with prevalence rate of $2.38 \%$. The nephrotic syndrome patients were prescribed for Prednisone, Prednisolone, Diuretics, Furosemide, Metolazone, Plasma protein, Albumin, Immunosuppressive agents, Mycophenolate mofetil, and Tacrolimus. These drugs were prescribed to reduce edema, removal of excess water and salts from body through kidney, immunosuppression and to increase oncotic pressure.

Prescribed drugs showed side effects in patients, side effects were skin infection, behavioural changes, blood in urine and decreased neutrophils. These side effects were due the presence of glucocorticoids, diuretic and ACE inhibitor drugs which are systematic in mode of action which resulted in their action on other sites also where no such action was required.

Co-morbidity related to nephrotic syndrome was also observed. Asthma, epilepsy, inflammatory bowel disease and prematurity were found in patients suffering from nephrotic syndrome. Methylxanthine, sedatives, aminosalicylates and miscellaneous drugs were prescribed for co-morbid patients.

\section{REFERENCES:}

1.Nephrotic Syndrome in Adults". National Institute of Diabetes and Digestive and Kidney Diseases. February 2014. Retrieved 9 November 2017.

2. Ferri, Fred F. (2017). Ferri's Clinical Advisor 2018 E-Book: 5 Books in 1. Elsevier Health Sciences. p. 889.

3. Kher, Kanwal; Schnaper, H. William; Greenbaum, Larry A. (2016). Clinical Pediatric Nephrology, Third Edition. CRC Press. p. 307.

4. Kelly, Christopher R.; Landman, Jaime (2012). The Netter Collection of Medical Illustrations - Urinary System e-Book. Elsevier Health Sciences. p. 101.

5. The paper is found on this link: http://www.kidneyfund.org/kidney-disease/other-kidneyconditions/rare-diseases/nephrotic-syndrome/.

6.The paper is found on this link: https://www.niddk.nih.gov/health-information/kidneydisease/children/childhood-nephrotic-syndrome.

7. The paper is found on this link: https://www.assignmentpoint.com/science/medical/nephrotic -syndrome.html.
8. Harold Friedman, H (2001). "General problems". Problem-oriented Medical Diagnosis(Seventh ed.). Lippincott Williams \& Wilkins. pp. 3 and 4.

9.Nephrotic syndrome. The Merck Manuals Online Medical Library. www.merckmanuals.com . Updated July 2013. Accessed July 7, 2014

10. Bakkaloglu SA, Schaefer F. Diseases of the kidney and urinary tract in children. In: Taal MW, Chertow GM, Marsden PA, et al., eds. Brenner and Rector's The Kidney. 9th ed. Philadelphia: Saunders; 2011: 2622-2643.

11. Curtis, Michael J.; Page, Clive P.; Walker, Michael J.A; Hoffman, Brian B. (1998). "Fisiopatología y enfermedades renales". Farmacología integrada. Harcourt. ISBN 8481743402.

12. Saz Peiro, Pablo. "El reposo prolongado" (PDF). Retrieved 8 Sep 2008.

13. Dietoterapia del síndrome nefrótico". Archived from the original on 2009-01-22. Retrieved 8 Sep 2008

14. Lista de alimentos ricos en sodio". Retrieved 8 Sep 2008.

15. Fluidoterapia: tipos de expansores" (PDF). Archived from the original (PDF) on 2008-09-20. Retrieved 8 Sep 2008. Plasma expanders are natural or synthetic substances (dextran, albumin...), that are able to retain liquid in the vascular space.

16. Lista de alimentos ricos en proteínas". Retrieved 8 Sep 2008. Expressed as grams per $100 \mathrm{~g}$ offood.

17. Sustitución de los alimentos ricos en grasas de la dieta". Archived from the originalon February 12, 2008. Retrieved 8 Sep 2008. Organizations in the US recommend that no more than $30 \%$ of total daily calorie intake is from fats.

18.Martín Zurro, Armando (2005). "Hipolipemiante, diuréticos, estatina.". Compendio de atención primaria: Conceptos, organización y práctica clínica (Segunda ed.). Elsevier España. p. 794. ISBN 8481748161.

19.Jiménez Alonso, Juan. "Profilaxis de los fenómenos tromboembólicos" (PDF). Retrieved 2008-09-14

20. Glassock RJ (August 2007). "Prophylactic anticoagulation in nephrotic syndrome: a clinical conundrum". J. Am. Soc. Nephrol. 18 (8): 2221 5. doi:10.1681/ASN.2006111300. PMID 17599972.

21. Rango Internacional Normalizado (INR)". Retrieved 2008-09-14.

22. The paper is found on this link: study.com/academy/lesson/what-is-comorbidity-definitionexamples-in-psychology.html

23. The paper is found on this link:https://www.nimh.nih.gov/health/statistics/what-isprevalence.html 